\title{
Body fatness or anthropometry for assessment of unhealthy weight status? Comparison between methods in South African children and adolescents
}

\author{
Eva Craig ${ }^{1,2, *}$, John Reilly ${ }^{1,3}$ and Ruth Bland ${ }^{1,2}$ \\ 'Section of Human Nutrition, University of Glasgow, Yorkhill Hospitals, QMH Tower 1 st Floor, Dalnair Street, \\ Glasgow G3 8SJ, UK: ${ }^{2}$ Africa Centre for Health and Population Studies, University of KwaZulu-Natal, \\ Mtubatuba, KwaZulu Natal, South Africa: ${ }^{3}$ School of Psychological Sciences \& Health, University of Strathclyde, \\ Glasgow, UK
}

Submitted 5 March 2012: Final revision received 19 July 2012: Accepted 17 August 2012: First published online 4 October 2012

\begin{abstract}
Objective: A variety of methods are available for defining undernutrition (thinness/ underweight/under-fat) and overnutrition (overweight/obesity/over-fat). The extent to which these definitions agree is unclear. The present cross-sectional study aimed to assess agreement between widely used methods of assessing nutritional status in children and adolescents, and to examine the benefit of body composition estimates. Design: The main objective of the cross-sectional study was to assess underweight, overweight and obesity using four methods: (i) BMI-for-age using WHO (2007) reference data; (ii) BMI-for-age using Cole et al. and International Obesity Taskforce cut-offs; (iii) weight-for-age using the National Centre for Health Statistics/WHO growth reference 1977; and (iv) body fat percentage estimated by bio-impedance (body fat reference curves for children of McCarthy et al., 2006). Comparisons were made between methods using weighted kappa analyses.

Setting: Rural South Africa.

Subjects: Individuals ( $n$ 1519) in three age groups (school grade 1 , mean age 7 years; grade 5, mean age 11 years; grade 9, mean age 15 years).

Results: In boys, prevalence of unhealthy weight status (both under- and overnutrition) was much higher at all ages with body fatness measures than with simple anthropometric proxies for body fatness; agreement between fatness and weight-based measures was fair or slight using Landis and Koch categories. In girls, prevalence of unhealthy weight status was also higher with body fatness than with proxies, although agreement between measures ranged from fair to substantial.

Conclusions: Methods for defining under- and overnutrition should not be considered equivalent. Weight-based measures provide highly conservative estimates of unhealthy weight status, possibly more conservative in boys. Simple body composition measures may be more informative than anthropometry for nutritional surveillance of children and adolescents.
\end{abstract}

Keywords Anthropometry Bio-impedance Undernutrition Overnutrition
Childhood obesity is rising to epidemic proportions in the developing world, adding a significant public health burden to countries where undernutrition remains common ${ }^{(1)}$; therefore the WHO highlights tackling childhood obesity as an urgent priority ${ }^{(2)}$. Child and adolescent overweight and obesity are related to an increase in non-communicable diseases $(\mathrm{NCD})^{(3)}$, while undernutrition is also known to substantially increase morbidity and mortality ${ }^{(4-7)}$.

Paradoxically, obesity is now common even in rural and under-developed areas, including those with a high prevalence of HIV and undernutrition ${ }^{(8)}$.

In rural South Africa, an estimated $60 \%$ of women aged 25-29 years were overweight $\left(\mathrm{BMI} \geq 25 \cdot 0 \mathrm{~kg} / \mathrm{m}^{2}\right)$ and $30 \%$ were obese $\left(\mathrm{BMI} \geq 30 \cdot 0 \mathrm{~kg} / \mathrm{m}^{2}\right)$ in $2006-2007^{(9)}$.
This was in an area at the epicentre of the HIV epidemic $^{(10,11)}$, where advanced HIV infection leads to weight loss, but prior to the widespread availability of HIV antiretroviral treatment ${ }^{(9)}$ which is likely to mitigate weight loss in HIV-infected individuals.

The NCD Alliance and the Lancet NCD Action Group proposed that the UN Summit in 2011 should prioritise several policies for low- and middle-income countries, one of which is population monitoring of $\mathrm{NCD}^{(12)}$. Population monitoring of child and adolescent underand overnutrition is based on simple anthropometric measures and indicators such as BMI-for-age ${ }^{(13)}$ but has become complicated lately by the plethora of new and more international approaches for defining unhealthy 
weight status ${ }^{(14)}$. A further complication is the increasing recognition of the potential value of having body composition measures rather than solely relying on simple proxies for fat and lean mass ${ }^{(15)}$. In order to assess the prevalence of unhealthy weight status, to allow an improved understanding of the causes and effects of child and adolescent under- and overnutrition in low- and middle-income countries, and to evaluate the impact of public health interventions, it is essential that major methodological questions in population monitoring of under- and overnutrition are resolved, including:

1. the effect of different definitions on the prevalence of unhealthy weight status; and

2. the extent to which a simple field measure of body composition adds value to the assessments of nutritional status provided by simple anthropometry.

The present study therefore examined the extent to which different approaches to defining weight status agreed with each other in rural Zulu children and adolescents, and the extent to which they agreed with assessments based on body fatness.

\section{Methods}

\section{Study setting}

The study was conducted at the Africa Centre (www. africacentre.com) in rural KwaZulu-Natal, an area with a high prevalence of HIV. In 2004, the overall HIV prevalence in the area among adults aged $15-54$ years was $27 \%$ for women and $13.5 \%$ for men; with $51 \%$ of women aged $25-29$ years and $44 \%$ of men aged $30-34$ years infected ${ }^{(10)}$.

The Africa Centre operates a large household and individual demographic surveillance in an area of $438 \mathrm{~km}^{2}$. Some 92000 individuals from 11000 households are surveyed twice annually, and all homesteads, buildings and amenities including schools, water supplies and roads are mapped using a geographic information system (GIS) ${ }^{(16,17)}$. In 2006, $77 \%$ of households in the surveillance area had access to piped water and toilet facilities ${ }^{(18)}$.

\section{Sample and sampling frame}

The present cross-sectional study used random sampling stratified by age, with the aim of recruiting 1500 (500 from three age groups) children and adolescents from within the demographic surveillance area (DSA) between April and December 2010. Children from school grades 1, 5 and 9 (corresponding to approximate ages of 7, 11 and 15 years, respectively) were recruited from local primary and secondary schools.

Schooling in South Africa begins at age 7 years; under the South African Schools Act 1996 schooling is compulsory up to age 15 years or until the completion of grade 9, whichever comes first. School enrolment rates across South
Africa are high, with Department of Education figures showing South Africa's gross enrolment rate to be $93 \%$ in the General Education and Training band (grades R-9) in 2009 ${ }^{(19)}$. The Statistics South Africa General Household Survey found that $98 \%$ of children aged $7-15$ years were in attendance at an education institution in $2009^{(20)}$.

It can be concluded, therefore, that school enrolment for children aged 7-15 years in South Africa is almost universal and as a result this population is largely accessible by recruitment via schools.

\section{Sampling at school level}

Secondary schools

Schools were chosen based on their rural/peri-urban setting determined using data from the Africa Centre GIS on their position within the DSA and further by their allocated school quintile. School quintiles are governmental assigned categories based on rates of income, unemployment and illiteracy within the school catchment area. They are broadly representative of school wealth, determining how much government funding schools receive per learner. Quintile 1 receives the highest funding and quintile 5 the least. Quintiles 1-3 are 'no fee' schools and quintiles 4 and 5 are fee-paying schools. There were no quintile 5 schools in this area and all schools included were in quintiles 1-4. This method of school selection, in order to obtain a representative sample, has been used previously in the South Africa Health of the Nation Study ${ }^{(21)}$. There are fifteen secondary schools in the DSA, six of which were sampled in the present study.

\section{Primary schools}

As the majority (over 90\%) of primary schools were in quintile 3 , quintiles were not used as a selection factor for younger children. Instead, primary schools were chosen using a randomly ordered list generated in Microsoft ${ }^{\circledR}$ Excel containing all forty-seven primary schools present in the DSA. Children were sampled from schools starting from number 1 on the list until the target number of individuals had been reached; children from twenty-two primary schools were included.

\section{Sampling at individual level}

All individuals in the appropriate grades had the study explained to them verbally and informed consent forms were distributed for them to take home. The class was then revisited on a later scheduled day to conduct measurements on individuals providing written consent. Participants were eligible for inclusion if they were enrolled into school grade 1, 5 or 9 in one of the chosen schools; signed informed consent was obtained from their caregiver and assent from themselves; and they were in attendance at school on the day of assessment. The study was conducted according to the guidelines laid down in the Declaration of Helsinki and all procedures involving 
Table 1 Representativeness of the study sample compared with the population of the demographic surveillance area (DSA)

\begin{tabular}{|c|c|c|c|c|c|c|c|c|c|}
\hline & \multicolumn{3}{|c|}{ Age (7 years) } & \multicolumn{3}{|c|}{ Age (11 years) } & \multicolumn{3}{|c|}{ Age (15 years) } \\
\hline & Full DSA & Present study & $P$ value & Full DSA & Present study & $P$ value & Full DSA & Present study & $P$ value \\
\hline Total $(n)$ & 1665 & $343^{*}$ & & 1742 & $377 \ddagger$ & & 1864 & $357 \S$ & \\
\hline Electricity at home (\%) & $58 \cdot 6$ & $69 \cdot 1$ & $0.003+$ & $57 \cdot 5$ & $60 \cdot 5$ & 0.414 & $59 \cdot 0$ & $63 \cdot 6$ & 0.200 \\
\hline Access to piped water (\%) & $56 \cdot 2$ & $60 \cdot 1$ & $0 \cdot 31$ & $55 \cdot 5$ & $57 \cdot 8$ & 0.524 & $56 \cdot 4$ & $63 \cdot 3$ & 0.06 \\
\hline
\end{tabular}

*343 matched out of $514=66.7 \%$.

tSignificant difference between DSA and present study.

$\$ 377$ matched out of $503=75 \cdot 0 \%$.

$\$ 357$ matched out of $502=71 \cdot 1 \%$.

human subjects were approved by the Biomedical Research Ethics Committee, University of KwaZulu-Natal.

Representativeness of the study sample in relation to the overall DSA population was examined using two indicators of socio-economic status: the presence of piped water in the home and the availability or otherwise of a connection to the electricity grid. Study participants were asked for their DSA household identification number at the time of enrolment. Using this identification number and other unique identifying data (including name, date of birth and parents' names), about $70 \%$ of the enrolled study sample in each grade was matched to their household data from the DSA, the remaining $30 \%$ was unmatched due to a lack of identifying data. Summary data on the extent to which the sample for the present study matched the general population, as described by DSA data, are given in Table 1 .

\section{Measurements}

Height was measured twice for each child to the nearest $0 \cdot 1 \mathrm{~cm}$ using a SECA stadiometer. If the difference between the two measurements was greater than $5 \mathrm{~mm}$, a third measurement was taken and the two heights within $5 \mathrm{~mm}$ were recorded ${ }^{(22)}$. Weight and body fat measurements were carried out once using TANITA SC240MA bio-impedance digital scales. Weight and body fat were measured in light indoor clothing (shoes and socks removed). Weight was measured to the nearest $0 \cdot 1 \mathrm{~kg}$ and body fat estimated to the nearest $0 \cdot 1 \%$. On the TANITA device, 'non-athlete' was chosen as the standard mode and $0.5 \mathrm{~kg}$ was entered as the standard deduction for clothes weight. The TANITA device allows for gender, age and height in its measurements.

All measurements were carried out by two Zuluspeaking local research assistants, trained and supervised by one of the authors (E.C.).

\section{Four reference comparisons: reference data and definitions of underweight, thinness, overweight and obesity}

\section{BMI-for-age using WHO (2007) reference data} WHO AnthroPlus software was used for application of the WHO Reference 2007 for children aged 5-19 years ${ }^{(23,24)}$ (hereafter referred to as 'WHO 2007'). Underweight, overweight and obesity were defined by BMI-for-age as a $Z$-score of $<-2,>+1$ and $\leq+2$ (equivalent to BMI $\geq 25 \cdot 0 \mathrm{~kg} / \mathrm{m}^{2}$ at 18 years) and $>+2$ (equivalent to $\mathrm{BMI} \geq 30 \cdot 0 \mathrm{~kg} / \mathrm{m}^{2}$ at 18 years), respectively.

\section{Weight-for-age using the National Center for Health Statistics/WHO growth reference 1977}

The WHO 2007 weight-for-age references are only available up to age 10 years; therefore, the National Center for Health Statistics (NCHS)/WHO growth reference 1977 (hereafter referred to as 'NCHS/WHO') was used to calculate weight-for-age for the full sample (using the EpiInfo program available from the US Centers for Disease Control and Prevention $(\mathrm{CDC}))^{(25,26)}$. The following weight-for-age categories were used to define weight status: $Z$-score $<-2$ as underweight, $Z$-score $>+1$ and $\leq+2$ as overweight and $Z$-score $>+2$ as obese.

\section{BMI-for-age using Cole et al. and International Obesity Taskforce cut-offs}

The BMI-for-age cut-offs of Cole et al. and the International Obesity Taskforce (IOTF) were also applied to the data ${ }^{(27-29)}$ (hereafter referred to as 'Cole-IOTF'). The Cole et al. ${ }^{(29)}$ approach was used to define thinness, corresponding to a conceptually equivalent BMI at age 18 years of $<18 \cdot 5 \mathrm{~kg} / \mathrm{m}^{2}$, and the IOTF approach ${ }^{(27)}$ was used to define overweight and obesity, conceptually equivalent to a BMI at age 18 years of $25 \cdot 0-29 \cdot 9 \mathrm{~kg} / \mathrm{m}^{2}$ for overweight and $\geq 30 \cdot 0 \mathrm{~kg} / \mathrm{m}^{2}$ for obesity.

\section{Body composition measurement from bio-impedance} Body fat estimates from bio-impedance were categorised into under-fat, healthy, over-fat and obese, by age and sex, using McCarthy et al.'s ${ }^{(30)}$ body fat reference curves for children (hereafter referred to as 'McCarthy 2006'). This reference was not ideal given that it was based on Caucasian children and adolescents. However, due to the absence of other applicable body fat references, this was used in the present study.

\section{Statistical analysis}

Data were analysed using the STATA statistical software package version $11 \cdot 0$.

To determine the agreement between the different definitions of underweight, thinness, under-fat, overweight, 
obesity and over-fat, the weighted kappa statistic $\left(\boldsymbol{\kappa}_{\mathrm{w}}\right)$ was used. This statistic was calculated with four categories, namely underweight, healthy weight, overweight and obese. Landis and Koch's ${ }^{(31)}$ categories were used to interpret the output: $\boldsymbol{\kappa}_{\mathrm{w}}=0-0 \cdot 20$ indicates slight agreement; $\boldsymbol{\kappa}_{\mathrm{w}}=0.21-0.40$ fair agreement; $\boldsymbol{\kappa}_{\mathrm{w}}=0.41-0.60$ moderate agreement; $\kappa_{\mathrm{w}}=0 \cdot 61-0.80$ substantial agreement; and $\kappa_{\mathrm{w}}=0 \cdot 81-1 \cdot 00$ indicates almost perfect agreement.

\section{Results}

\section{Descriptive data of study participants}

Table 1 provides summary data on the representativeness of the study sample, by comparison with the DSA population, using information from the Africa Centre Household Surveillance (C Newell, personal communication, September 2011). Only one variable was found to be significantly different in one age group between the present study and the DSA population, suggesting the present sample was broadly socio-economically representative of the wider DSA. The population resident within the DSA is essentially Zulu (governed predominantly by the Zulu land ownership system where the king controls who can build houses); therefore, there was no need to account for differences in ethnicity between participants.

A total of 1519 participants were measured, with an overall consent rate of approximately $70 \%$. Characteristics of study participants are shown in Table 2. Median BMI-for-age $Z$-score, using WHO 2007, was negative (i.e. $Z$-score $<0$ ) at all time points except for girls in grade 9. Body fat percentage in boys was lower in the middle than in the youngest age group and lower still in the oldest age group; however, in girls the opposite was the case, with the highest level in the oldest age group. Median height-for-age $Z$-score was negative in both sexes and at all three age groups.

\section{Differences in the prevalence of underweight, overweight and obesity using different antbropometric measures (body fat, BMI-for-age, weight-for-age) in boys}

Prevalence of healthy and unhealthy weight status by method and age group in boys is summarised in Table 3. The body fat method produced the lowest estimates of healthy weight status in all age groups when compared with BMI-for-age and weight-for-age methods. Discrepancies between weight status assessments based on weight and BMI were strikingly different from those obtained by body fatness measures; however, this difference was not significant for those in grade 1 (Table 3). Prevalence of healthy weight status in boys by bio-impedance was $74 \%, 46 \%$ and $36 \%$ in grades 1,5 and 9 , respectively, compared with 81-92\% using NCHS/WHO, 78-82\% using Cole-IOTF and 86-88\% using WHO 2007 definitions.

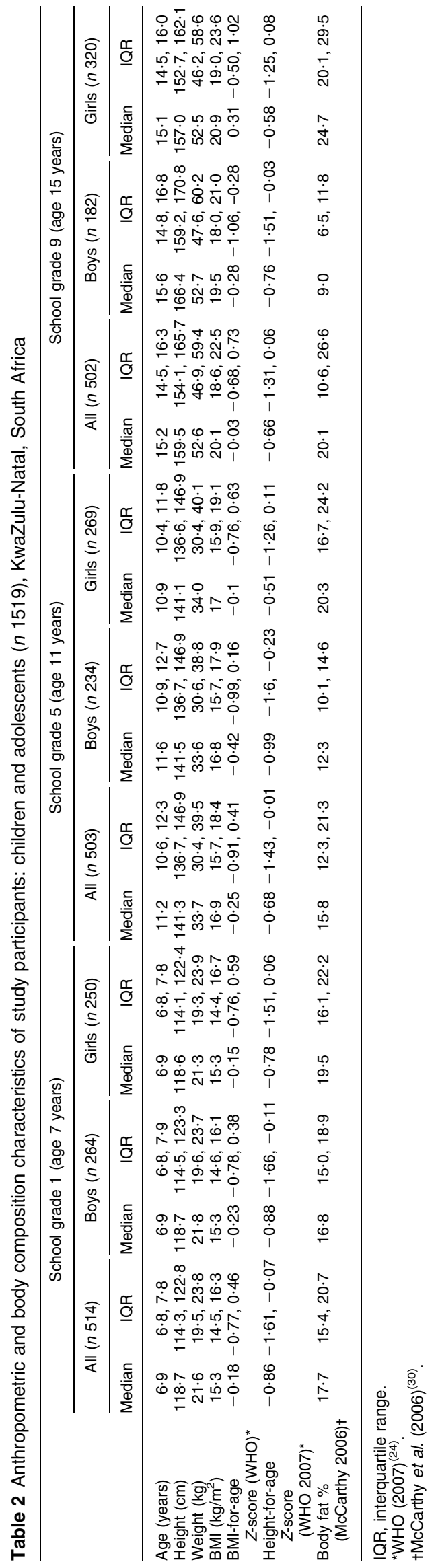


Table 3 Prevalence of four categories of weight status (underweight, healthy, overweight and obesity) using four international references among boys, KwaZulu-Natal, South Africa

\begin{tabular}{|c|c|c|c|c|c|c|c|c|c|c|}
\hline \multirow[b]{2}{*}{ Weight status } & \multirow[b]{2}{*}{ Method } & \multicolumn{3}{|c|}{ Grade 1 (age 7 years) } & \multicolumn{3}{|c|}{ Grade 5 (age 11 years) } & \multicolumn{3}{|c|}{ Grade 9 (age 15 years) } \\
\hline & & $n$ & $\%$ & $95 \% \mathrm{Cl}$ & $n$ & $\%$ & $95 \% \mathrm{Cl}$ & $n$ & $\%$ & $95 \% \mathrm{Cl}$ \\
\hline \multirow[t]{4}{*}{ Underweight* } & BMI-for-age (WHO 2007) ${ }^{(24)}$ & 9 & $3 \cdot 4$ & $1 \cdot 8,6 \cdot 4$ & 12 & $5 \cdot 2$ & $3 \cdot 0,8 \cdot 8$ & 11 & $6 \cdot 2$ & $3 \cdot 5,10 \cdot 8$ \\
\hline & BMI-for-age (Cole-IOTF) ${ }^{(27,29)}$ & 42 & $16 \cdot 0$ & $12 \cdot 0,20 \cdot 9$ & 30 & $12 \cdot 9$ & $9 \cdot 2,17 \cdot 8$ & 26 & $15 \cdot 8$ & $11 \cdot 0,22 \cdot 1$ \\
\hline & Weight-for-age (NCHS/WHO) ${ }^{(25)}$ & 16 & $6 \cdot 2$ & $3 \cdot 8,9 \cdot 8$ & 9 & 3.9 & $2 \cdot 1,7 \cdot 2$ & 12 & $7 \cdot 6$ & $4 \cdot 4,12 \cdot 8$ \\
\hline & Body fat \% (McCarthy 2006) ${ }^{(30)}$ & 23 & $8 \cdot 8$ & $5 \cdot 9,12 \cdot 8$ & 114 & $48 \cdot 7$ & $42 \cdot 4,55 \cdot 1$ & 110 & $60 \cdot 4$ & $53 \cdot 2,67 \cdot 3$ \\
\hline \multirow[t]{4}{*}{ Healthy weight +} & BMI-for-age $(\text { WHO 2007) })^{(24)}$ & 230 & $87 \cdot 5$ & $82 \cdot 9,90 \cdot 9$ & 202 & $86 \cdot 7$ & $81 \cdot 7,90 \cdot 5$ & 152 & $85 \cdot 9$ & $80 \cdot 0,90 \cdot 3$ \\
\hline & BMI-for-age (Cole-IOTF) ${ }^{(27,29)}$ & 212 & $80 \cdot 6$ & $75 \cdot 4,84 \cdot 9$ & 191 & $82 \cdot 0$ & $76 \cdot 5,86 \cdot 4$ & 129 & $78 \cdot 2$ & $71 \cdot 3,83 \cdot 8$ \\
\hline & Weight-for-age (NCHS/WHO) ${ }^{(25)}$ & 211 & $81 \cdot 2$ & $76 \cdot 0,85 \cdot 4$ & 213 & $91 \cdot 8$ & $87 \cdot 6,94 \cdot 7$ & 138 & $87 \cdot 3$ & $81 \cdot 3,91 \cdot 7$ \\
\hline & Body fat \% (McCarthy 2006) ${ }^{(30)}$ & 195 & $74 \cdot 4$ & $68 \cdot 8,79 \cdot 3$ & 107 & $45 \cdot 7$ & $39 \cdot 5,52 \cdot 1$ & 66 & $36 \cdot 3$ & $29 \cdot 6,43 \cdot 5$ \\
\hline \multirow[t]{4}{*}{ Overweightł } & BMI-for-age (WHO 2007) & 22 & $8 \cdot 4$ & $5 \cdot 6,12 \cdot 3$ & 11 & $4 \cdot 7$ & $2 \cdot 7,8 \cdot 3$ & 10 & $5 \cdot 7$ & $3 \cdot 1,10 \cdot 1$ \\
\hline & BMI-for-age (Cole-IOTF) ${ }^{(27,29)}$ & 8 & 3.0 & $1 \cdot 6,5 \cdot 9$ & 7 & $3 \cdot 0$ & $1 \cdot 5,6 \cdot 1$ & 8 & $4 \cdot 9$ & $2 \cdot 5,9 \cdot 3$ \\
\hline & Weight-for-age (NCHS/WHO) $)^{(25)}$ & 25 & $9 \cdot 6$ & $6 \cdot 6,13 \cdot 8$ & 8 & 3.5 & $1 \cdot 8,6 \cdot 7$ & 7 & $4 \cdot 4$ & $2 \cdot 2,8 \cdot 9$ \\
\hline & Body fat \% (McCarthy 2006) ${ }^{(30)}$ & 36 & $13 \cdot 7$ & $10 \cdot 1,18 \cdot 4$ & 5 & $2 \cdot 1$ & $0.9,4 \cdot 9$ & 1 & 0.6 & $0 \cdot 1,3 \cdot 1$ \\
\hline \multirow[t]{4}{*}{ Obese§ } & BMI-for-age (WHO 2007) & 2 & 0.8 & $0 \cdot 2,2 \cdot 7$ & 8 & $3 \cdot 4$ & $1 \cdot 8,6 \cdot 6$ & 4 & $2 \cdot 3$ & $0 \cdot 9,5 \cdot 7$ \\
\hline & BMI-for-age (Cole-IOTF) ${ }^{(27,29)}$ & 1 & 0.4 & $0 \cdot 1,2 \cdot 1$ & 5 & $2 \cdot 2$ & $0.9,4.9$ & 2 & $1 \cdot 2$ & $0 \cdot 3,4 \cdot 3$ \\
\hline & Weight-for-age (NCHS/WHO) ${ }^{(25)}$ & 8 & $3 \cdot 1$ & $1 \cdot 6,6 \cdot 0$ & 2 & $0 . \overline{9}$ & $0 \cdot 2,3 \cdot 1$ & 1 & $0 . \overline{6}$ & $0.1,3.5$ \\
\hline & Body fat \% (McCarthy 2006) ${ }^{(30)}$ & 8 & $3 \cdot 1$ & $1 \cdot 6,5 \cdot 9$ & 8 & $3 \cdot 4$ & $1 \cdot 7,6 \cdot 6$ & 5 & $2 \cdot 8$ & $1 \cdot 2,6 \cdot 3$ \\
\hline
\end{tabular}

IOTF, International Obesity Taskforce; NCHS, National Center for Health Statistics.

*Underweight: WHO $2007=Z$ score of $<-2$; IOTF = equivalent to BMl at age 18 years of $<18.5 \mathrm{~kg} / \mathrm{m}^{2} ; \mathrm{NCHS} / \mathrm{WHO}=Z$-score of $<-2$; McCarthy $2006=$ body fat $\%$ ranging from 0 to $12 \%$ depending on age.

thealthy weight: WHO $2007=Z$ score of $\geq-2$ and $\leq+1 ;$ IOTF $=$ equivalent to BMI at age years 18 of $18 \cdot 5-24 \cdot 9 \mathrm{~kg} / \mathrm{m}^{2} ; \mathrm{NCHS} / \mathrm{WHO}=\mathrm{Z}$-score of $\geq-2$ and $\leq+1$; McCarthy $2006=$ body fat $\%$ ranging from 10 to $23 \%$ depending on age.

$\ddagger$ Overweight: WHO $2007=Z$-score of $>+1 ;$ IOTF = equivalent to BMI at age 18 years of $25 \cdot 0-29 \cdot 9 \mathrm{~kg} / \mathrm{m}^{2} ; \mathrm{NCHS} / \mathrm{WHO}=Z$-score of $>+1$ and $\leq+2 ;$ body fat $\%=$ ranging from 20 to $28 \%$, depending on age.

§Obese: WHO $2007=Z$-score of $>+2$; IOTF = equivalent to BMl at age 18 years of $\geq 30 \cdot 0 \mathrm{~kg} / \mathrm{m}^{2} ; \mathrm{NCHS} / \mathrm{WHO}=Z$-score of $>+2 ;$ McCarthy $2006=$ body fat $\%$ ranging from $24 \%$ depending on age.

Table 4 Prevalence of four categories of weight status (underweight, healthy, overweight and obesity) using four international references among girls, KwaZulu-Natal, South Africa

\begin{tabular}{|c|c|c|c|c|c|c|c|c|c|c|}
\hline \multirow[b]{2}{*}{ Weight status } & \multirow[b]{2}{*}{ Method } & \multicolumn{3}{|c|}{ Grade 1 (age 7 years) } & \multicolumn{3}{|c|}{ Grade 5 (age 11 years) } & \multicolumn{3}{|c|}{ Grade 9 (age 15 years) } \\
\hline & & $n$ & $\%$ & $95 \% \mathrm{Cl}$ & $n$ & $\%$ & $95 \% \mathrm{Cl}$ & $n$ & $\%$ & $95 \% \mathrm{Cl}$ \\
\hline \multirow[t]{4}{*}{ Underweight* } & BMI-for-age (WHO 2007) & 3 & $1 \cdot 2$ & $0.4,3.5$ & 5 & 1.9 & $0 \cdot 8,4 \cdot 3$ & 6 & 1.9 & $0 \cdot 9,4 \cdot 1$ \\
\hline & BMI-for-age (Cole-IOTF) ${ }^{(27,29)}$ & 38 & $15 \cdot 1$ & $11 \cdot 2,20 \cdot 1$ & 33 & $12 \cdot 3$ & $8 \cdot 9,16 \cdot 7$ & 25 & $8 \cdot 2$ & $5 \cdot 6,11 \cdot 8$ \\
\hline & Weight-for-age (NCHS/WHO) ${ }^{(25)}$ & 7 & $2 \cdot 8$ & $1 \cdot 4,5 \cdot 7$ & 5 & 1.9 & $0 \cdot 8,4 \cdot 3$ & 3 & $1 \cdot 0$ & $0 \cdot 3,2 \cdot 9$ \\
\hline & Body fat \% (McCarthy 2006) ${ }^{(30)}$ & 44 & $17 \cdot 7$ & $13 \cdot 4,22 \cdot 9$ & 53 & $19 \cdot 7$ & $15 \cdot 4,24 \cdot 9$ & 29 & $9 \cdot 1$ & $6 \cdot 4,12 \cdot 7$ \\
\hline \multirow{3}{*}{ Healthy weight +} & BMI-for-age (WHO 2007) $)^{(24)}$ & 214 & $85 \cdot 3$ & $80 \cdot 3,89 \cdot 1$ & 228 & $84 \cdot 8$ & $80 \cdot 0,88 \cdot 6$ & 227 & $72 \cdot 3$ & $67 \cdot 1,77 \cdot 0$ \\
\hline & $\begin{array}{l}\text { BMl-for-age (Cole-IOTF) })^{(27,29)} \\
\text { Weight-for-age (NCHS/WHO) }\end{array}$ & $\begin{array}{l}190 \\
185\end{array}$ & $\begin{array}{l}75 \cdot 7 \\
74 \cdot 9\end{array}$ & $\begin{array}{l}70 \cdot 0,80 \cdot 6 \\
69 \cdot 1,80 \cdot 0\end{array}$ & $\begin{array}{l}210 \\
244\end{array}$ & $\begin{array}{l}78 \cdot 1 \\
91 \cdot 0\end{array}$ & $\begin{array}{l}72 \cdot 8,82 \cdot 6 \\
87 \cdot 0,93 \cdot 9\end{array}$ & $\begin{array}{l}211 \\
264\end{array}$ & $\begin{array}{l}69 \cdot 2 \\
86 \cdot 9\end{array}$ & $\begin{array}{l}63 \cdot 8,74 \cdot 1 \\
82 \cdot 6,90 \cdot 2\end{array}$ \\
\hline & Body fat \% (McCarthy 2006) ${ }^{(30)}$ & 157 & $63 \cdot 1$ & $56 \cdot 9,68 \cdot 8$ & 193 & $71 \cdot 8$ & $66 \cdot 1,76 \cdot 8$ & 215 & $67 \cdot 2$ & $58 \cdot 0,68 \cdot 2$ \\
\hline \multirow[t]{4}{*}{ Overweight‡ } & BMI-for-age (WHO 2007) ${ }^{(24)}$ & 29 & $11 \cdot 6$ & $8 \cdot 2,16 \cdot 1$ & 32 & $11 \cdot 9$ & $8 \cdot 6,16 \cdot 3$ & 56 & $17 \cdot 8$ & $14 \cdot 0,22 \cdot 5$ \\
\hline & BMI-for-age (Cole-IOTF) ${ }^{(27,29)}$ & 18 & $7 \cdot 2$ & $4 \cdot 6,11 \cdot 1$ & 23 & $8 \cdot 6$ & $5 \cdot 8,12 \cdot 5$ & 53 & $17 \cdot 4$ & $13 \cdot 5,22 \cdot 0$ \\
\hline & Weight-for-age (NCHS/WHO) ${ }^{(25)}$ & 36 & $14 \cdot \overline{6}$ & $10 \cdot 7,19 \cdot 5$ & 16 & $6 \cdot 0$ & $3 \cdot 7,9 \cdot 5$ & 30 & $9 \cdot 9$ & $7 \cdot 0,13 \cdot 7$ \\
\hline & Body fat \% (McCarthy 2006) ${ }^{(30)}$ & 35 & $14 \cdot 1$ & $10 \cdot 3,18 \cdot 9$ & 17 & $6 \cdot 3$ & $3 \cdot 7,9 \cdot 2$ & 40 & $12 \cdot 5$ & $8 \cdot 3,15 \cdot 0$ \\
\hline \multirow[t]{4}{*}{ Obese§ } & BMI-for-age (WHO 2007) & 5 & $2 \cdot 0$ & $0 \cdot 8,4 \cdot 6$ & 4 & 1.5 & $0 \cdot 6,3 \cdot 8$ & 25 & 8.0 & $5 \cdot 5,11 \cdot 5$ \\
\hline & BMI-for-age (Cole-IOTF) $(27,29)$ & 5 & $2 \cdot 0$ & $0 \cdot 9,4 \cdot 6$ & 3 & $1 \cdot 1$ & $0 \cdot 4,3 \cdot 2$ & 16 & $5 \cdot 3$ & $3 \cdot 3,8 \cdot 4$ \\
\hline & Weight-for-age (NCHS/WHO) ${ }^{(25)}$ & 19 & $7 \cdot 7$ & $5 \cdot 0,11 \cdot 7$ & 3 & $1 \cdot 1$ & $0 \cdot 4,3 \cdot 2$ & 7 & $2 \cdot 3$ & $1 \cdot 1,4 \cdot 7$ \\
\hline & Body fat \% (McCarthy 2006) ${ }^{(30)}$ & 13 & $5 \cdot 2$ & $3 \cdot 1,8 \cdot 7$ & 6 & $2 \cdot 2$ & $1 \cdot 0,4 \cdot 4$ & 36 & $11 \cdot 3$ & $7 \cdot 8,14 \cdot 3$ \\
\hline
\end{tabular}

IOTF, International Obesity Taskforce; NCHS, National Center for Health Statistics.

*Underweight: $W H O 2007=Z$ score of $<-2$; IOTF = equivalent to BMI at age 18 years of $<18.5 \mathrm{~kg} / \mathrm{m}^{2}$; $\mathrm{NCHS} / \mathrm{WHO}=Z$-score of $<-2$; McCarthy $2006=$ body fat $\%$ ranging from 0 to $12 \%$ depending on age.

thealthy weight: WHO $2007=Z$ score of $\geq-2$ and $\leq+1 ;$ IOTF $=$ equivalent to BMI at age years 18 of $18 \cdot 5-24 \cdot 9 \mathrm{~kg} / \mathrm{m}^{2} ; \mathrm{NCHS} / \mathrm{WHO}=\mathrm{Z}$-score of $\geq-2$ and $\leq+1$; McCarthy $2006=$ body fat $\%$ ranging from 10 to $23 \%$ depending on age.

fOverweight: WHO $2007=Z$-score of $>+1$; IOTF $=$ equivalent to $\mathrm{BMI}$ at age 18 years of $25 \cdot 0-29 \cdot 9 \mathrm{~kg} / \mathrm{m}^{2} ; \mathrm{NCHS} / \mathrm{WHO}=Z$-score of $>+1$ and $\leq+2$; McCarthy 2006 = body fat $\%$ ranging from 20 to $28 \%$, depending on age.

§Obese: WHO $2007=Z$-score of $>+2$; IOTF $=$ equivalent to BMl at age 18 years of $\geq 30 \cdot 0 \mathrm{~kg} / \mathrm{m}^{2} ; \mathrm{NCHS} / \mathrm{WHO}=Z$-score of $>+2$; McCarthy $2006=$ body fat $\%$ ranging from $24 \%$ depending on age.

\section{Differences in the prevalence of underweight, overweight and obesity using different anthropometric measures (body fat, BMI-for-age, weight-for-age) in girls}

Prevalence of healthy and unhealthy weight status by method and age group in girls is summarised in Table 4 . The highest prevalence of underweight and lowest prevalence of healthy weight status were found using the body fat assessment for all three age groups in girls. In grades 1 and 9, there were no significant differences between body fat and Cole-IOTF estimates of underweight prevalence. Also, in grade 9, prevalence of healthy weight status was not significantly lower when using body fat assessment compared with Cole-IOTF or WHO 2007 definitions. 
Table 5 Comparison between methods used to define weight status - weighted kappa $\left(\kappa_{\mathrm{w}}\right), 95 \%$ confidence interval and interpretation according to Landis and Koch ${ }^{(31)}$ : children and adolescents ( $n$ 1519), KwaZulu-Natal, South Africa

\begin{tabular}{|c|c|c|c|c|c|c|}
\hline & \multicolumn{3}{|c|}{ Boys } & \multicolumn{3}{|c|}{ Girls } \\
\hline & $\kappa_{\mathrm{w}}$ & $95 \% \mathrm{Cl}$ & Interpretation ${ }^{(31)}$ & $\kappa_{\mathrm{w}}$ & $95 \% \mathrm{Cl}$ & Interpretation ${ }^{(31)}$ \\
\hline \multicolumn{7}{|c|}{ WHO BAZ ${ }^{(24)} /$ Cole-IOTF BAZ ${ }^{(27,29)}$} \\
\hline Grade 1 (age 7 years) & $0 \cdot 41$ & $0 \cdot 19,0.62$ & Fair & 0.54 & $0.39,0.69$ & Moderate \\
\hline Grade 5 (age 11 years) & 0.65 & $0.54,0.76$ & Substantial & $0 \cdot 61$ & $0.42,0.79$ & Moderate \\
\hline Grade 9 (age 15 years) & 0.66 & $0.46,0.86$ & Substantial & $0 \cdot 80$ & $0 \cdot 72,0 \cdot 88$ & Substantial \\
\hline \multicolumn{7}{|l|}{ WHO BAZ ${ }^{(24)} /$ body fat $\%^{(30)}$} \\
\hline Grade 1 (age 7 years) & 0.34 & $0.20,0.48$ & Fair & 0.42 & $0 \cdot 23,0 \cdot 61$ & Moderate \\
\hline Grade 5 (age 11 years) & 0.27 & $0.11,0.44$ & Fair & 0.44 & $0.29,0.58$ & Moderate \\
\hline Grade 9 (age 15 years) & $0 \cdot 13$ & $0.06,0.20$ & Slight & 0.68 & $0 \cdot 54,0 \cdot 81$ & Substantial \\
\hline \multicolumn{7}{|c|}{ Cole-IOTF BAZ ${ }^{(27,29)} /$ body fat $\%{ }^{(30)}$} \\
\hline Grade 1 (age 7 years) & 0.27 & $0.09,0.45$ & Fair & 0.51 & $0.39,0.63$ & Moderate \\
\hline Grade 5 (age 11 years) & 0.38 & $0.24,0.52$ & Fair & $0 \cdot 62$ & $0 \cdot 45,0.79$ & Substantial \\
\hline Grade 9 (age 15 years) & 0.24 & $0.03,0.46$ & Fair & $0 \cdot 70$ & $0.55,0.86$ & Substantial \\
\hline \multicolumn{7}{|c|}{ WHO BAZ ${ }^{(24)} / \mathrm{NCHS} / \mathrm{WHO} \mathrm{WAZ}^{(25)}$} \\
\hline Grade 1 (age 7 years) & 0.42 & $0.30,0.53$ & Moderate & 0.49 & $0 \cdot 36,0 \cdot 61$ & Moderate \\
\hline Grade 5 (age 11 years) & $0 \cdot 41$ & $0.24,0.59$ & Moderate & 0.52 & $0.35,0.69$ & Moderate \\
\hline Grade 9 (age 15 years) & 0.39 & $0.23,0.55$ & Fair & 0.49 & $0 \cdot 34,0 \cdot 65$ & Moderate \\
\hline \multicolumn{7}{|c|}{ Cole-IOTF BAZ ${ }^{(27,29)} / \mathrm{NCHS} / \mathrm{WHO} \mathrm{WAZ}^{(25)}$} \\
\hline Grade 1 (age 7 years) & 0.34 & $0 \cdot 12,0.57$ & Fair & 0.35 & $0 \cdot 21,0 \cdot 50$ & Fair \\
\hline Grade 5 (age 11 years) & 0.42 & $0.22,0.62$ & Moderate & 0.44 & $0.23,0.65$ & Moderate \\
\hline Grade 9 (age 15 years) & 0.55 & $0.31,0.78$ & Moderate & 0.49 & $0.45,0.53$ & Moderate \\
\hline \multicolumn{7}{|c|}{ Body fat $\%^{(30)} / \mathrm{NCHS} / \mathrm{WHO} \mathrm{WAZ}^{(25)}$} \\
\hline Grade 1 (age 7 years) & 0.32 & $0.08,0.56$ & Fair & 0.39 & $0 \cdot 17,0 \cdot 62$ & Fair \\
\hline Grade 5 (age 11 years) & $0 \cdot 15$ & $0.003,0.30$ & Slight & $0 \cdot 28$ & $0 \cdot 16,0.39$ & Fair \\
\hline Grade 9 (age 15 years) & $0 \cdot 15$ & $0.09,0.22$ & Slight & 0.44 & $0 \cdot 27,0 \cdot 61$ & Moderate \\
\hline
\end{tabular}

BAZ, BMI-for-age Z-score; IOTF, International Obesity Taskforce; NCHS, National Center for Health Statistics; WAZ, weight-for-age Z-score.

Discrepancies between the prevalences of unhealthy weight status obtained by body fat assessment $v$. weightand BMI-based approaches varied with age, but were generally smaller in girls than boys.

\section{Agreement between different methods of defining weight status as assessed by weighted kappa}

Agreement between the various methods when assessed by $\kappa_{\mathrm{w}}$ analysis was generally low, although worse for boys than girls (Table 5). In boys, the majority of comparisons yielded slight to moderate agreement with the only agreement classified as substantial being the grade 5 and 9 comparisons between WHO 2007 BMI-for-age and ColeIOTF thinness, overweight and obesity definitions based on BMI-for-age. All three comparisons of weight- or BMIbased assessments with body fat assessment produced agreements which were either slight or fair.

In girls, all agreements between methods were either moderate or substantial with the exception of the grade 1 Cole-IOTF BMI-for-age and NCHS/WHO weight-for-age comparison and the grades 1 and 5 body fat $v$. NCHS/ WHO weight-for-age comparisons, which were classified as fair.

\section{Discussion}

\section{Main findings and implications}

In the present study, the simple anthropometric methods used to define weight status produced estimates of unhealthy weight status that were markedly lower than estimates derived from body fatness measures; this discrepancy was greater in boys. Agreement between definitions based on the simple proxies for body fatness and body fatness assessments was only 'fair' ${ }^{\text {(31) }}$ in the boys and 'moderate-substantial' ${ }^{\text {(31) }}$ in the girls. Simple anthropometric definitions of overweight and obesity are known to define high body fat conservatively ${ }^{(32)}$, and the IOTF obesity definition is not equivalent in boys and girls $^{(32)}$. It is not clear why greater agreement was observed between anthropometric and body composition methods in girls than in boys in the present study, but this difference between the sexes applied to most of the anthropometric methods used, extending beyond the expected sex-related bias associated with the IOTF obesity definition $^{(32)}$. This issue merits further research as it would have important implications for future nutritional surveillance. Our study suggests that anthropometric nutritional surveillance might be more accurate in South African girls than boys.

Given the present results it may be possible that body fatness measures are more informative than simple proxies when assessing nutritional status, providing more realistic estimates of the prevalence of unhealthy weight status. Body fatness measures should perhaps be considered as preferred alternatives to simple weight-based measures in clinical settings and in public health applications such as surveillance. Bio-impedance as a field method is already widely used in surveillance of nutritional status throughout the developed world ${ }^{(33-35)}$ and it may be helpful in future 
surveillance of nutritional status in low- and middleincome countries. Importantly, the results of body fatness measures and simple proxies varied more significantly in the underweight and healthy weight categories than in the overweight and obese categories; the reasons for this difference warrant further research.

\section{Comparisons with other studies}

We are unaware of any studies that have compared the same approaches to defining weight status in rural South African children and adolescents. Few studies have considered definitions using a body composition reference or have compared assessments across the range of weight status (including both underweight and overweight/obesity), and even fewer have been able to evaluate the relatively new approach of Cole et al. ${ }^{(29)}$ to defining thinness. El-Ghaziri et al. ${ }^{(14)}$ compared the same anthropometric methods for defining weight status in Kuwaiti adolescents: they found that the international approaches (Cole 2007, IOTF 2000, WHO 2007 and CDC 2000) agreed well with each other; however, in the present study there were noticeable differences between these measures. Other studies have compared local and international references in children and adolescents, but with few studies from low- and middle-income countries and rural areas ${ }^{(36,37)}$

A recent systematic review $^{(38)}$ found that use of BMI-for-age with the Cole 2007 and IOTF 2000 method was a highly conservative approach to defining obesity, with generally much lower estimates of obesity prevalence when used in school-aged children than when national reference data and definitions based on BMI were used. Monasta et al. $^{(32)}$ found large differences in prevalence of overweight between Cole 2007 and IOTF $2000 v$. WHO 2007 references, with Cole 2007 and IOTF 2000 providing considerably higher prevalence of overweight compared with WHO 2007 reference data, and called for urgent attention to determine the optimal BMI cut-offs for WHO 2007 reference data.

South Africa currently uses several BMI references as the method of choice in surveillance of underweight, overweight and obesity (WHO 2007, WHO/NCHS 1977, WHO/CDC 1977, IOTF 2000) $)^{(21,39-43)}$.

Recent South African prevalence studies have used anthropometric methods exclusively, the BMI-for-age NCHS/WHO growth reference 1977 data for underweight and the IOTF approach for overweight/obesity ${ }^{(8,30,43)}$. These studies all used simple proxy measures for body composition and none has used the new Cole et al. thinness definition $^{(29)}$. One of the most recent South African studies, which is similar to the present study, was carried out within the Agincourt DSA among children aged 1-20 years ${ }^{(8)}$. In addition to BMI, waist circumference was measured, but no assessment of body fat was made. In line with the present study, their results demonstrated highest levels of overweight/obesity in the older female age groups.

\section{Study strengths and weaknesses}

The present study was novel as many of the constructs and definitions we used are relatively new (e.g. Cole et al.'s thinness definition ${ }^{(29)}$ ), with only limited evidence on their use to date. In addition, a great strength of the present study was the use of a measure of body fat as well as anthropometric measures, which are proxies for body fatness. The availability of body fatness data allowed us to deal tentatively with the issue of the validity of the simple anthropometric definitions, whereas previous studies have generally compared between anthropometric definitions of unknown validity. The conclusions in relation to the validity of the various anthropometric methods tested here depend in part on the accuracy of the body composition methodology used though, and this is discussed below. The present study also recruited a relatively high proportion of the total DSA population in each age group (Table 1).

The appropriateness of using all anthropometric measures, and body composition methods in particular, in ethnic groups is in slight doubt ${ }^{(44)}$. The extent to which reference data for weight or BMI or body fat should be ethnic-specific is not clear currently, but an important issue is that, at present, all recommended methods for children and adolescents are universal. The present study therefore serves to indicate that this approach possibly has limitations in certain ethnic groups. Further, a recent study found ethnic differences to increase with age ${ }^{(44)}$, and this effect of age on the extent to which body composition methods are ethnic-specific requires further investigation.

It is possible that the bio-impedance estimates of fatness are biased in a sex-specific manner as bio-impedance analysis errors can be very different (magnitude and direction) in boys compared with girls ${ }^{(45)}$. The use of the McCarthy 2006 references for body fat may have led to an over/underestimation of body fat in the present sample given that the reference was initially developed on Caucasian children and ethnic differences in body fat have previously been reported ${ }^{(44)}$. These ethnic differences, which show children and adolescents of South Asian and African-Caribbean ethnicity to have a higher body fat percentage than those of white ethnicity, may have an important role when using body fat measures to determine risk of obesity-related diseases such as type 2 diabetes ${ }^{(44)}$. Cross-validation of the McCarthy 2006 approach to using bio-impedance analysis to estimate body composition against a criterion method of body composition in nonEuropean populations would be useful before the method is adopted more widely.

The tentative recommendation from the present study to use a measure of body composition as opposed to a proxy could be problematic in low- and middle-income countries, especially in rural areas, given limited resources. Bioimpedance is probably the least expensive field option, but is more costly than equipment required for simple proxy measures of body composition which are usually based on weight and height. However, given that measures of body 
fatness may be more informative than simple anthropometry, and as the burden of NCD grows in low- and middle-income countries, this extra cost may be justified in future population surveillance.

\section{Conclusions}

The anthropometric methods we used for defining unhealthy weight status in children and adolescents do not produce equivalent assessments when applied in rural South Africa. Moreover, agreement between proxy measures of unhealthy weight status and measures of body fatness was generally low, with very conservative estimates of unhealthy weight status arising from the weightand BMI-based measures. There is a substantial body of evidence to suggest that BMI-based assessments of body fatness tend to be conservative compared with body composition methods ${ }^{(38)}$ and therefore it is reasonable to assume that this may also be the case in the present study, irrespective of any doubts over the accuracy of the body composition method used here. Bio-impedance measures of body fatness probably produce a more realistic estimate of the prevalence of unhealthy weight status; however, it is important that an ethnic-specific reference is agreed upon before this method is used as a standard surveillance measure.

\section{Acknowledgements}

Sources of funding: The Yorkhill Children's Foundation (YCF) provided a PhD studentship to E.C. Fieldwork took place at the Africa Centre for Health and Population Studies, which is funded by the Wellcome Trust (core grant GR065377/Z/01/H). Conflict of interest: None declared. Authors' contributions: E.C. contributed in study concept/design, implementation of the study, data collection and analysis, interpretation of the data and writing of the manuscript. J.R. contributed in study concept/design, interpretation of the data, reviewing and revising the manuscript for intellectual content and accurate formatting. R.B. contributed in study concept/ design, oversight of the fieldwork, interpretation of the data, reviewing and revising the manuscript for intellectual content and accurate formatting. Acknowledgements: The authors thank Busisiwe Masuku and Thembalethu Zulu for their contribution to the fieldwork; Colin Newell for assistance with the database; the Africa Centre Community Advisory Board and the principals, educators and learners of the participating schools; and Marie-Louise Newell for her helpful comments on the manuscript.

\section{References}

1. Popkin BM \& Gordon-Larsen P (2004) The nutrition transition: worldwide obesity dynamics and their determinants. Int J Obes Relat Metab Disord 28, Suppl. 3, S2-S9.
2. World Health Organization (2011) Global Strategy on Diet, Physical Activity and Health. http://www.who.int/dietphysical activity/childhood/en/ (accessed November 2011).

3. Reilly JJ \& Kelly J (2011) Long-term impact of overweight and obesity in childhood and adolescence on morbidity and premature mortality in adulthood: systematic review. Int J Obes (Lond) 35, 891-898.

4. Horton R (2008) Maternal and child undernutrition: an urgent opportunity. Lancet 371, 179.

5. Food and Agriculture Organization of the United Nations (2006) State of Food Insecurity in the World. Rome: FAO.

6. Black RE, Allen LH, Bhutta ZA et al. (2008) Maternal and child undernutrition: global and regional exposures and health consequences. Lancet 371, 243-260.

7. Sachs JD \& McArthur JW (2005) The Millennium Project: a plan for meeting the Millennium Development Goals. Lancet 365, 347-353.

8. Kimani-Murage EW, Kahn K, Pettifor JM et al. (2010) The prevalence of stunting, overweight and obesity, and metabolic disease risk in rural South African children. $B M C$ Public Health 10, 158.

9. Barnighausen T, Welz T, Hosegood V et al. (2008) Hiding in the shadows of the HIV epidemic: obesity and hypertension in a rural population with very high HIV prevalence in South Africa. J Hum Hypertens 22, 236-239.

10. Welz T, Hosegood V, Jaffar S et al. (2007) Continued very high prevalence of HIV infection in rural KwaZulu-Natal, South Africa: a population-based longitudinal study. AIDS 21, 1467-1472.

11. Barnighausen T, Hosegood V, Timaeus IM et al. (2007) The socioeconomic determinants of HIV incidence: evidence from a longitudinal, population-based study in rural South Africa. AIDS 21, Suppl. 7, S29-S38.

12. Beaglehole R, Bonita R, Horton R et al. (2011) Priority actions for the non-communicable disease crisis. Lancet 377, 1438-1447.

13. Must A \& Anderson SE (2006) Body mass index in children and adolescents: considerations for population-based applications. Int J Obes (Lond) 30, 590-594.

14. El-Ghaziri M, Boodai S, Young D et al. (2011) Impact of using national $v$. international definitions of underweight, overweight and obesity: an example from Kuwait. Public Health Nutr 14, 2074-2078.

15. Wells JC \& Fewtrell MS (2006) Measuring body composition. Arch Dis Child 91, 612-617.

16. Tanser FC \& Le Sueur D (2002) The application of geographical information systems to important public health problems in Africa. Int J Health Geogr $\mathbf{1}, 4$.

17. Tanser F, Gijsbertsen B \& Herbst K (2006) Modelling and understanding primary health care accessibility and utilization in rural South Africa: an exploration using a geographical information system. Soc Sci Med 63, 691-705.

18. Tanser F, Hosegood V, Barnighausen T et al. (2008) Cohort profile: Africa Centre Demographic Information System (ACDIS) and population-based HIV survey. Int J Epidemiol 37, 956-962.

19. Department of Basic Education (2010) Education Statistics in South Africa 2009. Pretoria: Department of Basic Education.

20. Department of Basic Education (2010) Education in South Africa. http://www.education.gov.za/EducationinSA/tabid/ 327/Default.aspx (accessed August 2011).

21. Armstrong ME, Lambert MI, Sharwood KA et al. (2006) Obesity and overweight in South African primary school children - the Health of the Nation Study. S Afr Med J 96, 439-444.

22. de Onis M, Onyango AW, Van den Broeck J et al. (2004) Measurement and standardization protocols for anthropometry used in the construction of a new international growth reference. Food Nutr Bull 25, 1 Suppl., S27-S36. 
23. World Health Organization (2008) WHO AnthroPlus Software. http://www.who.int/growthref/tools/en/ (accessed April 2010).

24. de Onis M, Onyango AW, Borghi E et al. (2007) Development of a WHO growth reference for school-aged children and adolescents. Bull World Health Organ 85, 660-667.

25. World Health Organization (1986) Use and interpretation of anthropometric indicators of nutritional status. Bull World Health Organ 64, 929-941.

26. Dibley MJ, Goldsby JB, Staehling NW et al. (1987) Development of normalized curves for the international growth reference: historical and technical considerations. Am J Clin Nutr 46, 736-748.

27. Cole TJ, Bellizzi MC, Flegal KM et al. (2000) Establishing a standard definition for child overweight and obesity worldwide: international survey. BMJ 320, 1240-1243.

28. Cole TJ (1990) The LMS method for constructing normalized growth standards. Eur J Clin Nutr 44, 45-60.

29. Cole TJ, Flegal KM, Nicholls D et al. (2007) Body mass index cut offs to define thinness in children and adolescents: international survey. BMJ 335, 194.

30. McCarthy HD, Cole TJ, Fry T et al. (2006) Body fat reference curves for children. Int J Obes (Lond) 30, 598-602.

31. Landis JR \& Koch GG (1977) The measurement of observer agreement for categorical data. Biometrics 33, 159-174.

32. Monasta L, Lobstein T, Cole TJ et al. (2011) Defining overweight and obesity in pre-school children: IOTF reference or WHO standard? Obes Rev 12, 295-300.

33. Haroun D, Croker H, Viner RM et al. (2009) Validation of BIA in obese children and adolescents and re-evaluation in a longitudinal study. Obesity (Silver Spring) 17, 2245-2250.

34. Mueller WH, Harrist RB, Doyle SR et al. (2004) Percentiles of body composition from bioelectrical impedance and body measurements in US adolescents $8-17$ years old: Project HeartBeat!. Am J Hum Biol 16, 135-150.

35. Deurenberg P, Kusters CS \& Smit HE (1990) Assessment of body composition by bioelectrical impedance in children and young adults is strongly age-dependent. Eur J Clin Nutr 44, 261-268.
36. Baya Botti A, Perez-Cueto FJ, Vasquez Monllor PA et al. (2010) International BMI-for-age references underestimate thinness and overestimate overweight and obesity in Bolivian adolescents. Nutr Hosp 25, 428-436.

37. Kulaga Z, Litwin M, Tkaczyk M et al. (2010) The height-, weight-, and BMI-for-age of Polish school-aged children and adolescents relative to international and local growth references. BMC Public Health 10, 109.

38. Reilly JJ, Kelly J \& Wilson DC (2010) Accuracy of simple clinical and epidemiological definitions of childhood obesity: systematic review and evidence appraisal. Obes Rev 11, 645-655.

39. Armstrong ME, Lambert MI \& Lambert EV (2011) Secular trends in the prevalence of stunting, overweight and obesity among South African children (1994-2004). Eur J Clin Nutr 65, 835-840.

40. Monyeki KD, van Lenthe FJ \& Steyn NP (1999) Obesity: does it occur in African children in a rural community in South Africa? Int J Epidemiol 28, 287-292.

41. Puckree T, Naidoo P, Pillay P et al. (2011) Underweight and overweight in primary school children in eThekwini district in KwaZulu-Natal, South Africa. Afr J Prim Health Care Fam Med 3, issue 1, art. \#203.

42. Norris SA, Griffiths P, Pettifor JM et al. (2009) Implications of adopting the WHO 2006 Child Growth Standards: case study from urban South Africa, the Birth to Twenty cohort. Ann Hum Biol 36, 21-27.

43. Reddy SP, Resnicow K, James S et al. (2009) Underweight, overweight and obesity among South African adolescents: results of the 2002 National Youth Risk Behaviour Survey. Public Health Nutr 12, 203-207.

44. Shaw NJ, Crabtree NJ, Kibirige MS et al. (2007) Ethnic and gender differences in body fat in British schoolchildren as measured by DXA. Arch Dis Child 92, 872-875.

45. Reilly JJ, Gerasimidis K, Paparacleous N et al. (2010) Validation of dual-energy X-ray absorptiometry and footfoot impedance against deuterium dilution measures of fatness in children. Int J Pediatr Obes 5, 111-115. 